\title{
EDITORIAL
}

\section{Curso Internacional de Endocrinología, Diabetes y Metabolismo}

\footnotetext{
s muy grato para mí, como endocrinóloga y cartagenera, darles la bienvenida a este magno evento, nuestro 1 VI Curso Internacional de Endocrinología, Diabetes y Metabolismo, donde podremos conjugar el deber con el placer.
}

La consolidación de este curso como un evento que convoca la asistencia masiva de médicos generales y especialistas afines nos impone la necesidad ineludible de mantener la actualización como atractivo principal y, por ende, la extensión de las fronteras de lo conocido, interactuando con otras especialidades, retroalimentándonos mutuamente para el bien de nuestros pacientes.

Así pues, tendremos temas como trastornos del sueño y su impacto en el metabolismo, presentado por el Dr. Octavian Ioachimescu, de la Universidad de Emory, en Atlanta; lo nuevo en dislipidemia, por el Dr. Paul Duell, de la División de Enfermedades Metabólicas de la Universidad de Oregon; el manejo del diabético hospitalizado, a cargo del Dr. Umpierrez, de la Universidad de Emory; riesgo vs. beneficio de los suplementos proteinícos en fitness, presentado por el Dr. John Duperly, de la Universidad de los Andes; ablación de nódulos tiroideos, por los Doctores Xavier Serrés y Claudia Caracela, radiólogos de España y Perú; la realidad de los "remedios caseros" achiote, canela, balsamina y otras hierbas para controlar la diabetes, por el Dr. Hernando Vargas.

Excelentes temas puntuales, que los invito a revisar en el programa científico y así se preparen a disfrutar, en mi noble ciudad, de jornadas académicas laboriosas, en un marco de belleza y hospitalidad únicos, combinando el deber de actualizarnos con el placer de compartir con amigos y colegas “Otra noche en Cartagena”. ¡Bienvenidos!

Cordialmente,

Yadira Villalba Yabrudy, MD.

Presidenta

VI Curso Internacional de Endocrinología, Diabetes y Metabolismo 